\title{
Predicting the number of public projects in the region as an indicator of economic stability
}

\author{
Olha Dupliak ${ }^{1}$, Olena Ovchynnikova ${ }^{1, *}$, and Oksana Zamazii ${ }^{2}$
}

\author{
${ }^{1}$ Khmelnytskyi National University, Department of Automated Systems and Modeling in Economics, Khmelnytskyi, Ukraine \\ ${ }^{2}$ Khmelnytskyi National University, Department of Accounting, Audit and Taxacion, Khmelnytskyi, Ukraine
}

\begin{abstract}
The article examines the issues of submitting applications and receiving funding for public projects depending on the demographic situation in the region. It is shown that the activity of the population in submitting applications for community projects contributes to the effectiveness of investing in the development of cities and regions. The dynamics of project submission in connection with the permanent population of Khmelnytskyi region is analyzed. In the course of the analysis, it was found that women make up the largest share among both the population and those who submit social projects. According to age characteristics, in spite of an increase in the proportion of the older age groups, mainly younger and middle age groups of the population develop community-based projects. The gender trend identified during the study indicates that women are more active in local processes than men who more closely coordinate these projects with government agencies. According to these statistics, a forecast is provided as to allocation of funds for the public projects' financing.
\end{abstract}

Today social projects do not surprise anyone. Throughout the country, in every place, many different community projects are implemented, submitted to the vote or rejected. Is it possible to predict the number of public projects for the future? Does the number of community projects depend on the total number of the population in the area?

The public budget (participation budget, participatory budget) is an important tool for direct e-democracy, which develops the culture of self-government. It contributes to the participation of the population in the development of the city, the formation of its priorities and the effective formation and use of the city budget. As a rule, the budget of participation is a part of the city budget, in which the inhabitants of the city independently choose what they spend, by voting. The results of this vote have direct effect, regardless of the decision of the officials and deputies.

As the practice of more than 2000 cities in different countries shows, they use their specific approaches to budgeting. However, these approaches are based on the increase in the participation of urban population in their development, formation of consciousness of citizens, tax loyalty, increase of social capital, increase of the index of happiness, formation of investment attractiveness and successfulness of the cities [1].

In the city budget of 2018 in the Khmelnytskyi region the significant activity of the population in the public projects is observed. Therefore, in our opinion, it is appropriate to follow the dependence of applications submitted to participation in public projects in the region relative to its demographic indicators. This will make it possible to predict the probability of allocating funds to certain community projects of the region and to predict the amount of their financing.

The activity of attracting the population of the territory is a prerequisite for the effectiveness of the implementation of a public project where it will be implemented. Otherwise, the funds spent on a public project are perceived by the population as a simple investment in ordinary construction, reorganization, improvement of certain objects and the natural reaction to it is rejection, and subsequently counteraction to its implementation. Therefore, the International Organization for Migration invites specialized nongovernmental organizations to express their interest in participating as a partner of the project on social cohesion of the population, which is manifested in the assessment of the following indicators [2]:

1) activity of the local population, emergence of new leaders and initiative groups;

2) the level of knowledge and skills of public activists;

3 ) the level of trust to local authorities.

The growth of these indicators will demonstrate the successful introduction of public projects in the given territory.

In its implementation, a public project requires several stages. The first stage is the creation or design of the project. The second one is writing and submitting a project, and the final stage is voting for the project. All of them are extremely important, where each of them reflects both the degree of activity of the public in the life of the region, and the degree of relevance for the distribution and use of the budget funds of the region.

As the realities of our country show, the introduction of decentralization reforms contributes not only to the formation of a new generation of local politicians and

* Corresponding author: veleslavaovch@gmail.com 
local government officials who would be interested in the development of community projects, but the change in the status of territorial communities creates a number of promising tasks that cannot be carried out without public participation.

Reforms have positively influenced the order of forming the budget of the territory (region, city). A national online network was created to control the share of expenditures and it provides the opportunity to use the allocated funds for the purpose of the community or the project.

Each city has its own platform which reflects all submitted projects. The platform has its structure according to the division of the city on the areas or neighborhoods. That is, in order to solve a certain social or communal problem of a certain neighborhood, it is necessary to find a site through the Internet and clearly formulate what needs to be changed (Fig. 1).

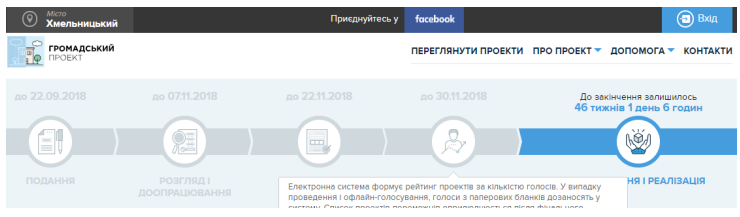

Fig. 1. Example of the site [3].

By monitoring the site of Khmelnytskyi region public projects, the archive was found starting only from 2017. According to the data, the public projects were submitted for not all declared categories. The largest number of submitted applications came in the category "Education", where 25 projects were registered. In the second place is the category "Housing and Utility Services", where the number of applications was 18 , in the third place was "Culture", where the number of applications equaled 15. Accordingly, "Health Protection" - 13, "Environmental Protection" - 4, "Social Protection" - 3, "Sport" - 2, and "Bicycle infrastructure", "Security and public order", "Road economy", "Energy saving", "Mass media", "Telecommunications, communications and information technologies", "Transport" - 0. Of these, the number of rejected in different categories was 25 applications from 80 submitted. In the "Culture" category 6 projects were rejected, "Housing and Utility Services" - 14, "Health" 1, "Environmental Protection" - 2, "Education" - 1 . Thus, 12 implemented projects out of 80 submitted projects will be studied: "Health Protection" - 5 applications, "Education" - 3, "Culture" - 2, "Social Protection" - 1, "Sport" - 1. For their implementation the funding was allocated in the amount of 979417 UAH.

In 2018, the number of applications submitted increased. The funding of them was also increased and reached 444581 UAH. The category "Education" takes the lead (Fig. 2).

Consequently, 21 projects were implemented in the amount of 1965302 UAH. According to the previous year, the number of applications that were implemented increased by 9 more (Fig. 3).
Submitted projects by category

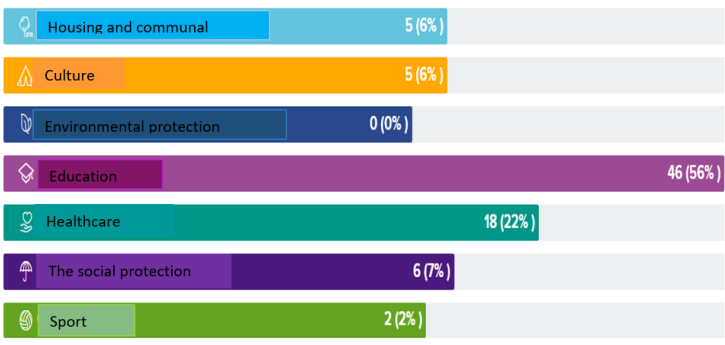

Fig. 2. Graphic chart of the submitted applications in 2018.

Projects winners by category

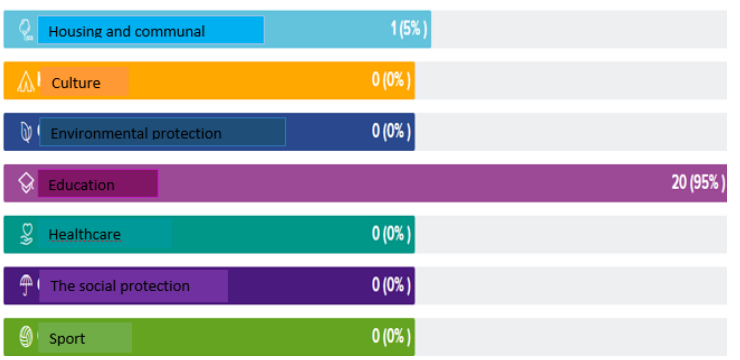

Fig. 3. Visual information of statistical data on the winning projects in 2018.

In our work, we propose to explore the relationship, on one hand, of the population's activity of the Khmelnytskyi region in the implementation of community projects with the dynamics of the existing population of the region. On the other hand, we propose to prove the dependence of the number of applications for various social projects on the actual distribution of the budget.

So, we illustrate the interrelation of the Khmelnytskyi region population activity in the public projects with the dynamics of the existing population. The number of the existing population in the Khmelnytskyi region in the period from 1995 to 2019 slightly decreased. Thus, by February 1, 2019, it amounted to 1 million 263.6 thousands of people comparing to 1 million 517 thousands of people in 1995 [4]. The dynamics of this indicator is presented in Fig. 4.

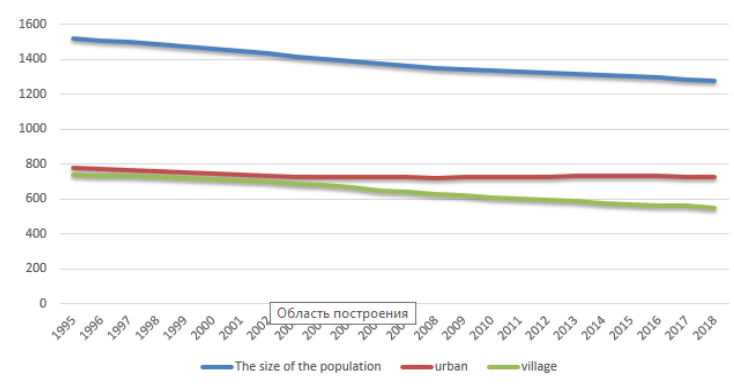

Fig. 4. Dynamics of the existing population of the Khmelnytskyi region.

As can be seen from Fig. 2, during 1995-2018 there is a tendency for a decrease in the Khmelnytskyi region population. In the world of modern trends, the fact that the share of the rural population decreases from $49 \%$ to $43 \%$ in the investigated period is logical. At the same 
time, the number of urban population remains almost unchanged (747 thousand people in 2000 and 723 thousand people in 2018), although its share in the total population has increased to $57 \%$.

So, as the starting point of analysis we take the index of urban population, since its share in the total population number is about $57 \%$. On the other hand, taking into account the level of education and social consciousness of the urban population, of course there is an increased interest in the community activity of the city and the region compared to the rural population.

Interestingly, the website of Khmelnytskyi's public projects maintains the statistics of the authors submitting applications. This allows us to determine the distribution of applications for participation in public projects based on the gender of their authors (Fig. 5).

Registered 68 authors

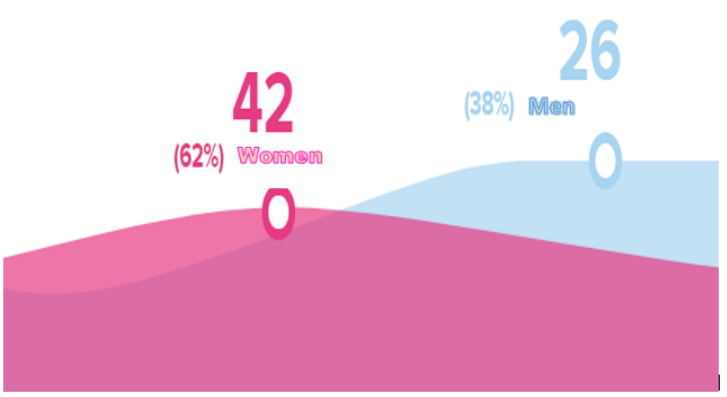

Fig. 5. Gender distribution by the authors of applications in 2018.

As statistics show, in the Khmelnytskyi region the number of women at the beginning of 2019 overstates the number of men by 91 thousand people, or $7.16 \%$ (Fig. 6). By the way, the global male to female ratio over the past twenty years has shifted toward increasing of male proportions (from $45.8 \%$ in 1995 to $46.4 \%$ in 2018).

Permanent population

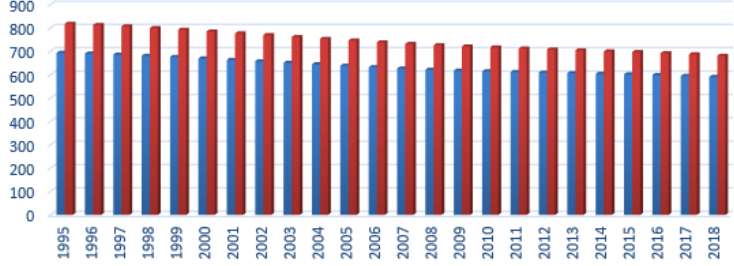

- men women

Fig. 6. Correlation of men and women in the Khmelnytskyi region.

However, if we investigate the gender distribution of the applications by the authors and the ratio of men and women to the overall structure of the population of the region in 2018, then the majority of the female population (by $7.15 \%$ over the male population) submitted $24 \%$ of the applications more than the male population ( $62 \%$ of applications filed by women, against $38 \%$ of applications submitted by men). This suggests that the female part of the population, even in matters of general social importance, is more active [5]. And despite the lack of significant influence in decision making in government or executive bodies, their civic attitude is the driving force in the implementation of community projects [6].

By 2019, 102 projects have already been submitted by 79 authors for a total amount of 12579563 UAH. In this year's projects the gender proportion is again seen as a predominant factor of the female part (Fig. 7).

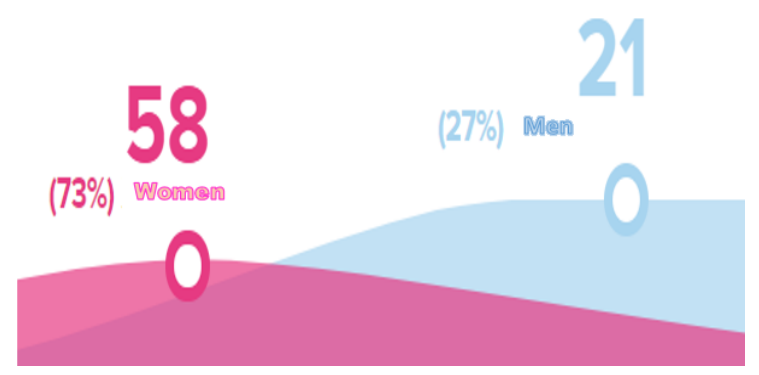

Fig. 7. Gender distribution by the authors of applications in 2019.

There is also a clear tendency in the increase in the number of applications made by women in comparison to men (the overbalance for this year is already $46 \%$ ) (Fig. 7).

Let's consider the age structure of the Khmelnytskyi region population (Fig. 8).

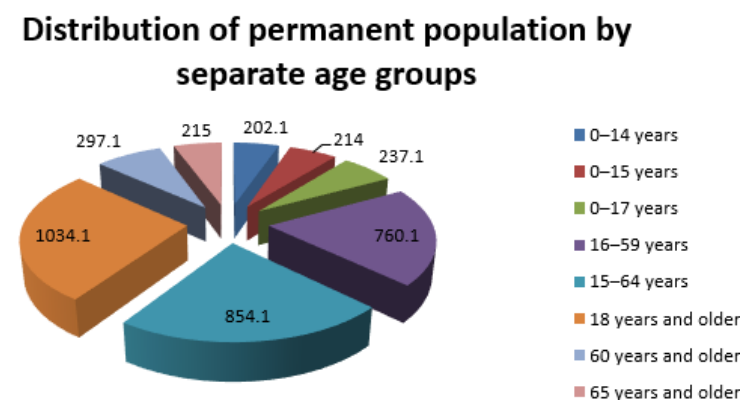

Fig. 8. Age structure of the Khmelnytskyi region population in 2018.

The largest proportion of the Khmelnytskyi region population is the age group of employable people (18 years and older) $-81.3 \%$.

If we consider the distribution by age group of "younger than employable age", "employable age" and "older than employable age", one can see that the proportion of the population of working age overstates the population of younger age and the population over 60 (59\% vs. $18 \%$ and $23 \%$ respectively). Taking into account such a significant age gap in the definition of employable age (from 16 to 59 years), this greatly complicates the analysis of population activity in public projects (Fig. 9). As the practice shows, not always people of the upper limit of the "employable age" category can be called socially active.

Returning to the analysis of the Khmelnytskyi region community projects website, the average age of the most active population is from 35 to 45 years, with the increase in the proportion of young active population who submit their projects to implementation [7]. 


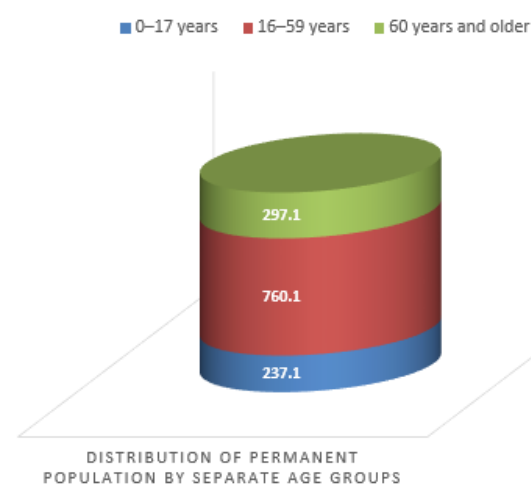

Fig. 9. Distribution of the Khmelnytskyi region population by age groups in 2018.

Proving the dependence of the number of applications for various social projects on the actual distribution of the budget of the region requires the analysis of the following data.

Thus, the budget of the Khmelnytskyi region in 2018 was formed as follows:

1) incomes of the region budget make 8484847.9 thousand UAH, including:

- general fund revenues of the region budget are 7900964.6 thousand UAH;

- revenues of the special fund of the region budget are 583883.3 thousand UAH;

2) expenditures of the region budget in the amount of 8484547.9 thousand UAH, including:

- expenditures of the general fund of the region budget are 7889126.6 thousand UAH;

- expenditures of the special fund of the region budget are 595421.3 thousand UAH;

3) repayment of credits to the region budget is 1290.7 thousand UAH, including:

- repayment of credits to the special fund of the region budget is 1290.7 thousand UAH;

4) granting loans from the region budget is 1590.7 thousand UAH, including:

- granting of credits from the general fund of the region budget is 300.0 thousand UAH;

- granting of loans from the special fund of the region budget is 1290.7 thousand UAH;

5 ) the surplus of the general fund of the region budget is 11538.0 thousand UAH [8].

We forecast the activity of the population in submitting applications for public projects in relation to the size of the declared budget using the built-in forecast function "FORECAST" of the Excel spreadsheets (Fig. 10).

\begin{tabular}{|r|r|r|r|r|r|}
\hline Years & $\begin{array}{c}\mathrm{X} j, \\
\text { Period }\end{array}$ & $\begin{array}{c}Y \\
Y j \\
\text { Financing of } \\
\text { public } \\
\text { projects, UAH }\end{array}$ & Forecast & Minimum forecast & $\begin{array}{c}\text { Maximum } \\
\text { forecast }\end{array}$ \\
\hline 2017 & 0 & 979417 & 979417 & 979417 & 979417 \\
\hline 2018 & 1 & 444581 & 444581 & 444581 & 444581 \\
\hline 2019 & 2 & 1965302 & 1965302 & 1965302 & 1965302 \\
\hline 2020 & & & 2192667.56 & 1006843.289 & 3378491.838 \\
\hline 2021 & & & 2604108.26 & 1395032.033 & 3813184.479 \\
\hline
\end{tabular}

Fig. 10. Forecast value of financing of public projects in three scenarios.
This function calculates or predicts a value based on the available figures. $Y$ is predicted for a given value of $X$. Known values are the available values of $X$ and $Y$, and the new value is predicted by linear regression.

Using this function, one can predict the future of any economic task that can be described by a number of variables (sales volumes, inventory requirements, consumer preferences, etc.).

In our case, this function will predict the rate of funding of public projects in order to determine the effective value of the amount of funds that should be allocated for the implementation of community projects in the region [9].

Thus, according to the data obtained with the help of linear forecasting, it is possible to propose three scenarios for the development of the situation: the standard value of the forecast, the minimum and maximum value.

Using data on the Khmelnytskyi region, such as the amount of funding and the number of applications for participation in public projects in 2017-2019, it is possible to propose predictions as of 2021. As can be seen from Figure 11, even with such modest growth rates of applications for public projects, there will be an increase in the allocation of funds for their financing. Based on real data of the Khmelnytskyi region budget, the amount of allocated funds for public projects will increase from 8484447.9 UAH to $227365.56 \mathrm{UAH}$. It also requires a corresponding increase in the budget. The average increase in the budget should amount to $10.8 \%$ annually.

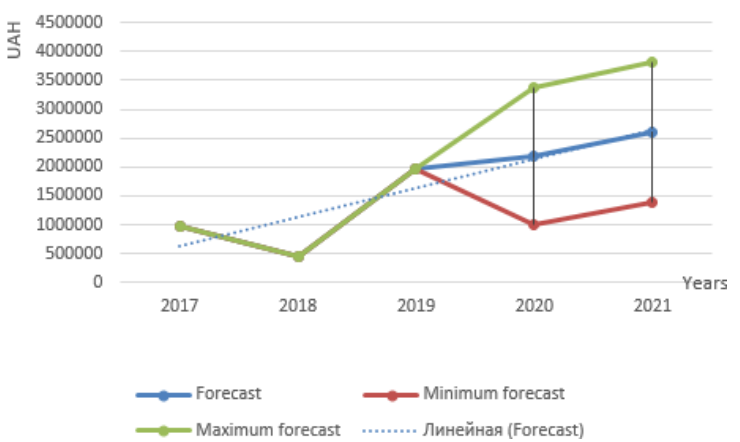

Fig. 11. The predictive value of public projects financing

So, summing up the above stated, let us note that the public budget (participative budget) is a democratic process of discussion and decision making in which every resident (regardless of gender) of any settlement determines how to spend part of the local budget.

As the experience of the developed countries and the practice of open areas shows, in order to ensure the participation of the population, it is necessary:

1) to attract, first and foremost, an active part of the population (leaders of local enterprises, deputies, intellectuals, entrepreneurs, etc.);

2) to bring the initial ideas of the project to the active part of the population and involve representatives of public in discussing the issues that concern them personally; 
3) to gradually expand the number of participants by attracting mass media (newspapers, radio, television);

4) to ensure the expression of opinions and ideas of all public areas, on the basis of which to formulate a joint view on the project implementation;

5) to make appropriate adjustments to the project.

Participation of the population creates the necessary effect: the project is implemented, people are activated, and the project is facilitated. However, planning of participation is much easier than providing. The main problem is the lack of initiative from the population. It is necessary to touch the interests of people very delicately so that they dare to participate.

The initial stage of public budget formation, as a participatory practice, is an effective information campaign. Informing about different stages was carried out through various channels of communication: radio, television, newspapers, flyers, announcements, organization of meetings, etc., which will contribute to the formation of not only effective methodological basis of the project, but also it will avoid unnecessary financial costs for its implementation [10].

According to the Khmelnytskyi region research, the majority of women and the population of the young and middle age groups are involved in the submission of public projects. It is they who are socially active and the innovation and investment development of the regions depends on them.

According to experts-practitioners on the implementation of public projects in the territories of different countries, with whom it is impossible to disagree, it is expedient to use the possible directions of improvement of the public budget process in domestic practice:

1) by strengthening the community of practitioners of the public budget, strengthening formal and informal links through holding of international Participatory Practitioners' Forum, regional Participation forums, various events and actions;

2) by understanding the need for continuous improvement and change of the public budget;

3 ) by introducing new participatory practices, which will meet the needs and interests of local communities.

In our opinion, the activation of society in solving social and economic issues is a positive trend for the Khmelnitskyi region. The process of decentralization of the region is beneficial. The distribution of budget funds for the needs of society to achieve the goals has become a transparent process. In addition, if a public project is important and the region is interested in its implementation, voting for the selection of proposals increases. In the future, the implementation of such public projects will be useful for the economic growth of the region, because of the main motives of the economic behavior of business units in it. This will allow enterprises to integrate not only one industry but also an area (for example, within cluster entities) to implement competitive strategies and business development [11].

Thus, there is a double activation of a part of society. On the one hand, when society is engaged in allocating funds to needs, it becomes socially active; on the other hand, the change in the attitude to government towards confidence in it will lead to social and economic transformations not only of some areas of society, but also of the whole region and the country.

Consequently, the study of causal relationships between the state and citizen has allowed us to highlight the gender tendency of the activity of the Khmelnytskyi region community and to predict probable necessary amount for the implementation of community projects in the future period.

In the analysis of applications according to the gender issue, it was determined that women are more active than men. Such category of public projects in the Khmelnytskyi region as "Education" has the largest number of implemented projects in recent years, according to statistics. Based on the gender preference of women in this category, we can conclude that the leadership of this category is based on the number of applications submitted by public projects and their implementation.

The increase of applications in 2019 from the young people under 26 years of age is a positive trend indicating the development of civil society, the growth of creativity and innovative ideas in the formation of requests for public projects. On the other hand, it is the transparency of the system of budget formation and distribution, submission and implementation of community projects that enables young and active people to increase their confidence in the implementation of their own ideas.

Nevertheless, it is considered necessary to propose to the region and local authorities to introduce training and continuous improvement of qualification for all interested persons on the issues of writing and submitting applications for public projects to the region site. It would have expanded not only the number of participants in the implementation of region community projects, but also enhance the public activity in the life of the community.

\section{References}

1. Sharov, Yu.P. (ed.): Proc. of scientific-practical conference with international participation on Scientific and practical provision of development and cooperation of the united territorial communities, Dnipro, October 2016. DRIDU NADU, Dnipro (2016)

2. Eastern Europe Foundation. Public budgets from A to $\mathrm{Z}$ : Positive results of the development of public budgets. http://eef.org.ua/publichni-byudzhety-vida-do-ya-pozytyvni-pidsumky-rozvytku-gromadskyhbyudzhetiv (2018). Accessed 20 Feb 2019

3. Website Public project in the Khmelnytskyi. https://gp.khm.gov.ua/projects (2018). Accessed 23 Feb 2019

4. Site of the Main Department of Statistics in the Khmelnytskyi Region. http://www.statbrd.ic.km.ua/ukr/index.htm (2019). Accessed 20 Feb 2019 
5. Libanova, E.M. (ed.): Liudskyi rozvytok v Ukraini: sotsialni ta demohrafichni chynnyky modernizatsyi natsionalnoi ekonomiky (Human development in Ukraine: social and demographic factors modernization of the national economy). Ptoukha Institute for Demography and Social Studies of the National Academy of Sciences of Ukraine, Kyiv (2012).

6. Gerasymenko, G.V.: Non-balanced Human Development: Global Determinants and Challenges for Ukraine. Demography and Social Economy. 2(22), 44-55 (2014). doi:10.15407/dse2014.02.045

7. Berdanova, O.V., Vakulenko, V.M., Grinchuk, N.M., Koltun, V.S., Kuibida, V.S., Tkachuk, A.F.: Upravlinnia rozvytkom obiednanykh terytorialnykh hromad na zasadakh hromadskoi uchasti (Management of the united territorial communities' development on the basis of public participation). Kyiv (2017).

8. Site of the Khmelnytskyi Region Council. https://adm-km.gov.ua/wpcontent/uploads $/ 2018 / 03 / \% \mathrm{D} 0 \% 9 \mathrm{E} \% \mathrm{D} 0 \% \mathrm{~B} 1 \% \mathrm{D} 0 \%$ BB $\%$ D0\%B0\%D1\%81\%D0\%BD $\%$ D0\%B8\%D0\%B 9 $\% \mathrm{D} 0 \% \mathrm{~B} 1 \% \mathrm{D} 1 \% 8 \mathrm{E} \% \mathrm{D} 0 \% \mathrm{~B} 4 \% \mathrm{D} 0 \% \mathrm{~B} 6 \% \mathrm{D} 0 \% \mathrm{~B} 5 \%$ D1\%82-2018.pdf (2018). Accessed 20 Feb 2019

9. Public budget. Participation budget. Site information. https://gb.kyivcity.gov.ua/pages/history (2017). Accessed 20 Feb 2019

10. Reforms in Ukraine. Examination of carried state decisions. ICPS, Kyiv (2015)

11. Stadnyk, V., Izhevskiy, P., Zamazii, O., Goncharuk, A., Melnichuk, O.: Factors of enterprises' strategic selection of participation forms in integration formations. Problems and Perspectives in Management. 16(2), 90-101 (2018). doi:10.21511/ppm.16(2).2018.09 